\title{
THE ABSORPTION BY BOAR SPERMATOZOA OF ZINC BOUND TO LOW MOLECULAR WEIGHT LIGANDS
}

\author{
J. C. BOURSNELL AND E. A. NOBLE \\ A.R.C. Unit of Reproductive Physiology and Biochemistry, Cambridge*
}

(Received 21st January 1975)

\begin{abstract}
Summary. Most of the zinc accumulated by boar spermatozoa at $4^{\circ} \mathrm{C}$ from seminal plasma appears to arise from the low molecular weight zinc ligands. Zinc added to semen in low concentrations $(0.1$ to 0.6 $\mathrm{mm}$ ) is preferentially absorbed by the spermatozoa, particularly at $4^{\circ} \mathrm{C}$.
\end{abstract}

\section{INTRODUCTION}

Boursnell \& Mustill (1975), in quantitative studies on the uptake of zinc by boar spermatozoa, showed that only about half the zinc naturally present in boar seminal plasma was absorbed by the spermatozoa in samples of fresh semen cooled to $4^{\circ} \mathrm{C}$, and that further similar applications of fresh spermatozoa absorbed no more. They also showed that no extra haemagglutinin is absorbed by the native spermatozoa under these conditions.

Boursnell (1967) suggests that boar epididymal spermatozoa may absorb haemagglutinin from vesicular secretions during ejaculation. No more haemagglutinin is lost by the seminal plasma during prolonged storage of semen at room temperature and it is difficult to demonstrate further absorption of the haemagglutinin by considerable enhancement of the sperm concentration (Boursnell, 1967). Further absorption can, however, be demonstrated from seminal vesicle secretion under these conditions. This may be attributable to the greatly increased concentration of haemagglutinin (about $\times 30$; Boursnell \& Coombs, 1966; Boursnell \& Butler, 1973) in this fluid. One explanation is that an equilibrium exists between the concentration of haemagglutinin and the number of possible receptor sites on the boar sperm surface remaining unsaturated.

Boursnell \& Mustill (1975) also showed a loss of zinc-precipitable nitrogen when boar seminal plasma was repeatedly absorbed at $4^{\circ} \mathrm{C}$ with homologous spermatozoa. These observations thus appear to be at variance with those demonstrating similarities between the haemagglutinin and the zinc precipitable protein (Roberts et al., 1974a, b; Boursnell et al., 1975), but Boursnell et al. (1975) showed that the material precipitated by zinc from seminal plasma is a complex mixture of proteins containing material other than the haemagglutinin and the protein demonstrating zinc-precipitability after gel filtration.

\footnotetext{
* Postal address: Animal Research Station, 307 Huntingdon Road, Cambridge CB3 0JQ.
} 
It is obviously necessary as part of the exploration of this complex to investigate the nature of the ligand binding of the absorbable seminal plasma zinc before further progress can be made. Work reported in this paper is directed towards this problem.

\section{Boar semen}

\section{MATERIALS AND METHODS}

Whole semen was collected from three boars housed at the Animal Research Station and used within a few minutes of collection after removal of the gel on a nylon sieve.

\section{Centrifugation of semen}

This was carried out on a semi-micro scale as described by Boursnell \& Mustill (1975). The method permitted observations on three identical samples in every set of manipulations within an experiment, and accurate weight determinations of the damp and dry sperm pellets. Normal centrifugation at room temperature at $12,000 \mathrm{~g}$ for $15 \mathrm{~min}$ was used to prepare seminal plasma.

\section{Ultrafiltration}

The method described by Lavon et al. (1972) was employed.

\section{Zinc determinations}

These determinations followed the method described by Boursnell \& Mustill (1975).

\section{Washing of spermatozoa}

This was carried out using the sperm Ringer-phosphate solution at $\mathrm{pH} 7 \cdot 25$ described by Mann (1964).

\section{RESULTS}

\section{Zinc absorption by washed boar spermatozoa from a zinc citrate solution}

Samples $(0.6 \mathrm{ml})$ of a fresh semen collection were centrifuged and the sperm pellets washed once in sperm Ringer-phosphate. Sets of the washed pellets were treated at room temperature or $4^{\circ} \mathrm{C}$ for 75 min with solutions $(0.6 \mathrm{ml})$ of zinc acetate ( 0 to $0.6 \mathrm{~mm}$ ) in $0.15 \mathrm{M}-\mathrm{NaCl}, 6.6 \mathrm{~mm}$-tri-sodium citrate, $20 \mathrm{~mm}$ tris at $\mathrm{pH} 7 \cdot 45$. The results are shown in Text-fig. 1 .

A constant loss of weight occurred when the washed spermatozoa were drained. This was not encountered with unwashed spermatozoa. The mean ( \pm S.D.) room temperature weights were: not washed, $20.08+0.48 \mathrm{mg}$; washed, $14.51 \pm 0.92 \mathrm{mg}$ and the mean $4^{\circ} \mathrm{C}$ values were: not washed, $19.69 \pm 0.26 \mathrm{mg}$; washed, $15 \cdot 12 \pm 0.72 \mathrm{mg}$. Thus $72 \%$ and $77 \%$, respectively, of the washed spermatozoa were retained at the two temperatures.

The weights of the washed spermatozoa were used to calculate the relative concentrations of zinc in the spermatozoa $(\mu \mathrm{mol} / \mathrm{g})$ to compare with those of the applied zinc citrate $(\mathrm{mm}=\mu \mathrm{mol} / \mathrm{ml})$. The regression equations for these are similar, by arithmetic chance $\left(10^{-3} \times\right.$ wt of spermatozoa in $\mathrm{mg} \times$ atomic wt 


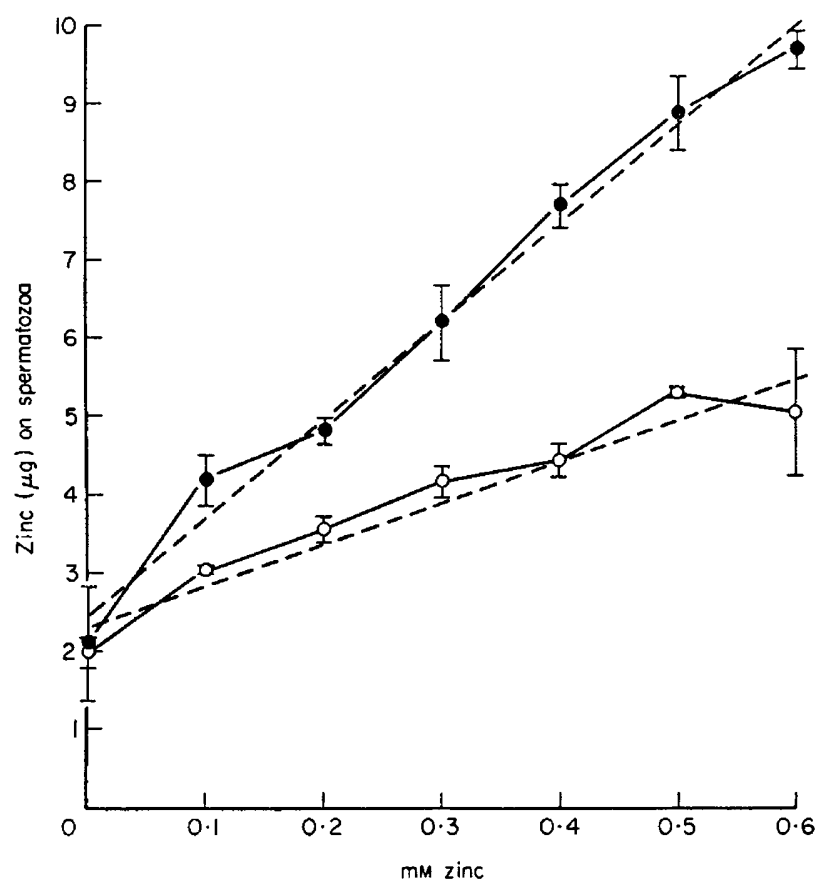

Text-FIG. 1. Zinc absorbed at $4^{\circ} \mathrm{C}(\bullet)$ and room temperature $(0)$ by washed boar spermatozoa from various concentrations of zinc in a citrate-NaCl-tris buffer at $\mathrm{pH} \mathrm{7.45.}$ Vertical lines represent the S.D. The equations for the regression lines $(---)$ of $\mu \mathrm{g} \mathrm{Zn}$ on spermatozoa are: $2 \cdot 37 \pm 0.23$ (S.D. $)+(\mathrm{mm} Z n$ applied $\times 5 \cdot 19 \pm 0.63)$ at room temperature,

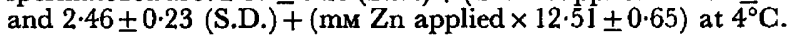

of zinc $\bumpeq 1)$, to the respective equations, given in the legend to Text-fig. 1, and the $\mu \mathrm{mol}$ zinc/g damp spermatozoa are: $2 \cdot 79 \pm 0.29$ (S.D.) $+(\mathrm{mm}$ zinc applied $\times 4.36 \pm 0.81$ ) at room temperature, and $2 \cdot 65 \pm 0.26+$ (mM zinc applied $\times 11.86 \pm 0.71)$ at $4^{\circ} \mathrm{C}$. The values for the slopes of these lines indicate a considerable concentration of the zinc by the spermatozoa compared with those of the applied zinc ( $\times 4.36$ and $\times 11.86$ respectively). A mean of $18 \pm 5 \%$ (S.D.) (room temperature) and $38 \pm 8 \%\left(4^{\circ} \mathrm{C}\right.$ ) of the total zinc applied was absorbed by the spermatozoa. Similar results were obtained in three other experiments even when $10 \mathrm{~mm}$ zinc was applied and unwashed spermatozoa were examined.

The absorption of added zinc by boar spermatozoa in native semen

Samples $(0.57 \mathrm{ml})$ of fresh semen were used with added volumes $(30 \mu \mathrm{l})$ of solutions of $6.6 \mathrm{~mm}$-tri-sodium citrate with $20 \mathrm{~mm}$-tris at $\mathrm{pH} 7.3$ and containing amounts of zinc acetate to give final concentrations of $0,0.2,0.4,0.6,0.8$ and $1.0 \mathrm{~mm}$. Sets of these samples were kept for $30 \mathrm{~min}$ at room temperature or $4^{\circ} \mathrm{C}$. Zinc determinations (Text-fig. 2) on the centrifuged drained pellets revealed linear increases with concentrations of added zinc between 0 and 0.8 $\mathrm{mm}$, greater at $4^{\circ} \mathrm{C}$ than at room temperature.

Similar responses were obtained with four other semen collections from two other boars. Attention was also paid to the effect of re-warming the cooled 


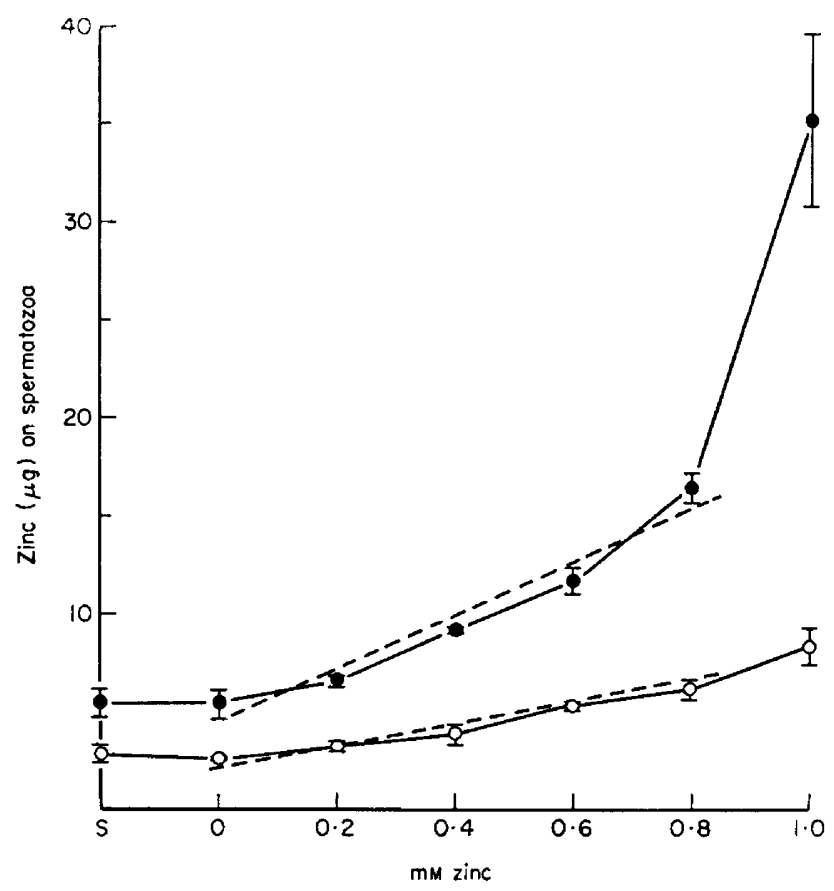

Text-Fig. 2. Zinc content, at $4^{\circ} \mathrm{C}(\bullet)$ and room temperature $(0)$, of spermatozoa centrifuged from fresh boar semen (S) to which had been added concentrations, to the values shown, of zinc in buffered citrate at $\mathrm{pH} 7.3$ as described. Vertical bars represent the S.D. Regression lines (-- ) for $\mu$ g zinc on spermatozoa for points at 0 to $0.8 \mathrm{~mm}$ obey the following equations: $2.11 \pm 0.37$ (S.D.) $+(\mathrm{mm}$ zinc added $\times 5.60 \pm 0.62)$ at room temperature, and $4.41 \pm 0.91$ (S.D. $)+(\mathrm{mm}$ zinc added $\times 13.49 \pm 1.85)$ at $4^{\circ} \mathrm{C}$.

zinc-treated semen samples. In one such experiment, zinc ( 0 to $0.8 \mathrm{~mm}$ ) was added as described above to three separate sets of semen, which were (i) cooled for $30 \mathrm{~min}$; (ii) similarly cooled and then re-warmed for $60 \mathrm{~min}$; or (iii) kept at room temperature for 90 min. Means $( \pm$ S.D.) of the zinc content $(\mu \mathrm{g})$ of the sperm pellets, calculated from the derived regression equations, were: (i) $16 \cdot 27 \pm 0.63$; (ii) $16.62 \pm 1.04$; and (iii) $10.95 \pm 1.69$. Damp pellet weights (mg) were: (i) $48 \cdot 25 \pm 0.44$; (ii) $37.72 \pm 0.93$; and (iii) $37.52 \pm 1.34$. Dry pellet weights $(\mathrm{mg}$ ) were: (i) $8.81 \pm 0.09$; (ii) $7 \cdot 88 \pm 0.22$; and (iii) $7 \cdot 83 \pm 0 \cdot 18$.

Zinc absorption by boar spermatozoa at $4^{\circ} \mathrm{C}$ from seminal plasma and from seminal plasma ultrafiltrates

Two $25 \mathrm{ml}$ portions of a fresh semen collection were centrifuged and the resulting seminal plasma samples were ultrafiltered at room temperature or at $1^{\circ} \mathrm{C}$. Samples $(0.6 \mathrm{ml})$ of the ultrafiltrates and of the original seminal plasma were absorbed three times successively at $4^{\circ} \mathrm{C}$ with spermatozoa from centrifuged samples $(0.6 \mathrm{ml})$ of the same semen. Zinc determinations were made on the fluids and sperm samples used. Three semen samples gave closely similar results. Two of these had similar seminal plasma zinc contents $(35.0$ and 35.8 $\mu \mathrm{g}$ zinc $/ \mathrm{ml}$ ) and the combined mean results are shown in Text-fig. 3 . 


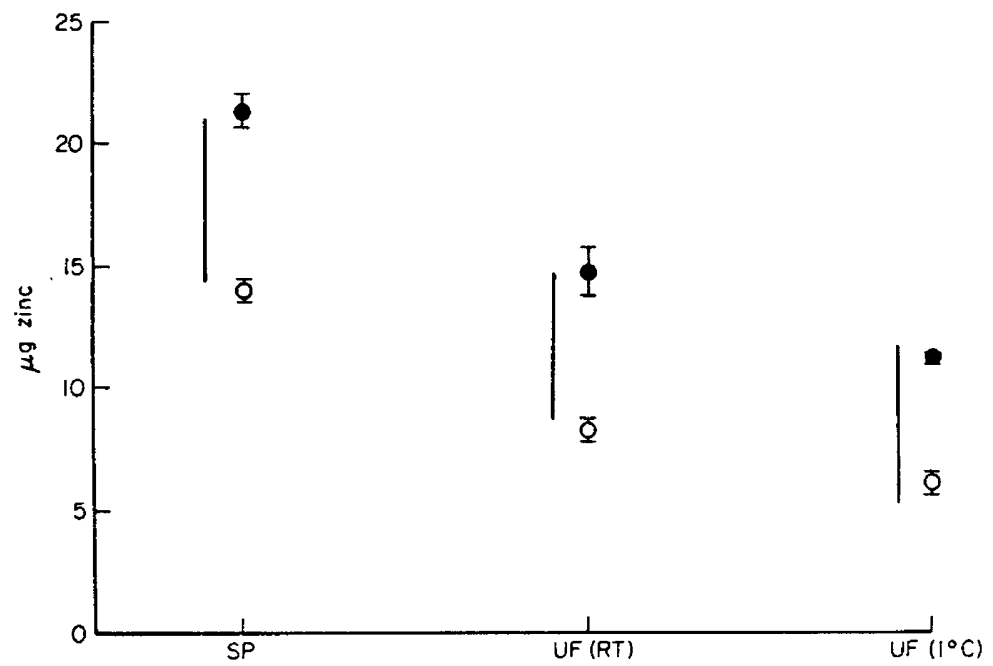

TExT-FIG. 3. Combined results of two experiments giving mean $\mu \mathrm{g}$ zinc/0.6 $\mathrm{ml}$ in (e) native boar seminal plasma (SP), seminal plasma ultrafiltrate obtained at room temperature (UF, RT) and corresponding ultrafiltrate obtained at $1^{\circ} \mathrm{C}$ (UF, $1^{\circ} \mathrm{C}$ ). The zinc concentrations $(O)$ of these fluids after three absorptions at $4^{\circ} \mathrm{C}$ by homologous spermatozoa are also plotted. Vertical bars represent the S.D. The lengths of the isolated vertical lines represent total $\mu \mathrm{g}$ zinc gained by all three of the respective samples of spermatozoa used for absorptions; these lines are positioned for comparison with the losses from the respective fluids.

\section{DISGUSSION}

The results reported in this paper reveal a number of unexpected facts. It would appear that most of the zinc accumulated by spermatozoa at $4^{\circ} \mathrm{C}$ arises from the low molecular weight zinc ligands in seminal plasma. This is shown by the avid absorption from zinc citrate by both washed and untreated spermatozoa. The studies with ultrafiltered seminal plasma strengthen this view. Ultrafiltrates obtained at room temperature and at $4^{\circ} \mathrm{C}$ were used in this work because Roberts et al. (1974a) showed that at the lower temperature more zinc was combined with high molecular weight material retained in the sac and a correspondingly lesser quantity appeared in the ultrafiltrate. This difference is apparent in the experiment shown in Text-fig. 3; it appears, however, not to be reflected by any lesser amount of zinc absorbed by the spermatozoa from the ultrafiltrate prepared at the lower temperature. The total absence of haemagglutinin in the ultrafiltrate (Lavon et al., 1972; Boursnell et al., 1973) is worthy of note, although, as these authors showed, the ultrafiltrate appears to contain about $4 \%$ of the seminal plasma proteins of relatively low molecular weight.

The present studies show that the competition of spermatozoa for zinc in citrate solution is partitioned in favour of the spermatozoa. The concentration of zinc in cooled spermatozoa in the experiments investigated is about $\times 12$ that in the aqueous fluid or that added to the semen. Spermatozoa also absorb zinc at room temperature to a lesser, but not inconsiderable, extent $(\times 4)$. The ligand associated with the spermatozoa that binds zinc has not been investigated. 
Zinc absorption was shown not to be directly connected with the increase in weight of the sperm pellet which occurs at $4^{\circ} \mathrm{C}$ and which is abolished by subsequent re-warming. Zinc absorption therefore appears irreversible by warming, but the weight increase is not so. The weight increase did not occur with the washed spermatozoa, and might merely be due to the cold-precipitated material from seminal plasma. This material does not appear to entrain extra zinc, a phenomenon which is being investigated on the lines suggested by Boursnell et al. (1975).

\section{AGKNOWLEDGMENT}

We would like to thank Dr M. M. Ketchel for his help with some of the early experiments in this work.

\section{REFERENCES}

BouRSNELL, J.C. (1967) Boar seminal haemagglutinin. II. Combination with red cells and spermatozoa. F. Reprod. Fert. 13, 297-314.

BoursNell, J.C. \& BuTLER, E.J. (1973) Studies on properties of the seminal gel of the boar using natural gel and gel formed in vitro. F. Reprod. Fert. 34, 457-465.

Boursnell, J.C. \& Coombs, R.R.A. (1966) A haemagglutinating factor in boar seminal plasma. 7. Reprod. Fert. 11, 139-144.

Boursnelx, J.C. \& MustiLl, E.A. (1975) The absorption of boar seminal zinc by cooled spermatozoa. 7. Reprod. Fert. 43, 153-157.

Boursnele, J.C., Briggs, P.A., Lavon, U. \& Butler, E.J. (1973) The association of zinc with some components of boar vesicular secretion and seminal plasma. II. Ultrafiltration and ethanolprecipitation studies. F. Reprod. Fert. 34, 73-77.

Boursnelt, J.C., Noble, E.A. \& ANDrews, M.G. (1975) Boar seminal zinc-precipitable protein and the haemagglutinin. F. Reprod. Fert. 45, 415-420.

Lavon, U., Boursnelt, J.C. \& Briggs, P.A. (1972) Further characterization of the proteins of boar seminal plasma by isoelectric focusing on polyacrylamide. 7. Reprod. Fert. 30, 165-167.

Mann, T. (1964) The Biochemistry of Semen and of the Male Reproductive Tract, p. 347. Methuen, London.

RoBerTs, T.K., Boursnell, J.C. \& BROWN, A.D. (1974a) The rôle of zinc in promoting the opalescence and cold precipitation of boarseminal plasma. II. Relationship of a zinc-precipitable protein with the haemagglutinin. F. Reprod. Fert. 37, 373-386.

Roberts, T.K., BoursnelL, J.G., Winsor, S.E. \& MustiLl, E.A. (1974b) The rôle of zinc in promoting the opalescence and cold precipitation of boar seminal plasma. III. Further observations on the nature of the cold-opalescence phenomenon. F. Reprod. Fert. 40, 411-422. 